Rev. Bras. Saúde Prod. Anim., Salvador, v.15, n.3, p.679-688 jul./set., 2014 http://www.rbspa.ufba.br ISSN 15199940

\title{
Relações entre treonina e lisina digestível em dietas para leitões desmamados aos 28 dias de idade
}

\author{
Relationship between threonine and lysine in diets for pigs weaned at 28 days of age
}

\author{
MAURÍCIO, Thamírys Vianelli1*; SOUZA, Matheus Faria de ${ }^{2}$; FERREIRA, Aloízio \\ Soares $^{3}$
}

${ }^{1}$ Universidade Federal do Espírito Santo, Centro de Ciências Agrárias, Programa de Pós-Graduação em Ciências Veterinárias, Alegre, Espírito Santo, Brasil. Bolsista Capes.

${ }^{2}$ Universidade Federal de Viçosa, Programa de Pós-Graduação em Zootecnia, Viçosa, Minas Gerais, Brasil. Bolsista CNPq.

${ }^{3}$ Universidade Federal de Viçosa, Departamento de Zootecnia, Viçosa, Minas Gerais, Brasil.

*Email para correspondência: t_vianelli@yahoo.com.br

\section{RESUMO}

Este estudo foi realizado com o intuito de se determinar as melhores relações de treonina digestível com lisina digestível para leitões dos 28 aos 49 dias de idade. Para isso foram utilizados 120 leitões híbridos comerciais com alto potencial genético para deposição de carne magra na carcaça, desmamados aos 28 dias de idade com peso inicial médio de $7,45 \mathrm{~kg}$. Os animais foram distribuídos em delineamento em blocos ao acaso, compostos por cinco tratamentos (relações de treonina digestível e lisina digestível) e controlando o peso inicial, com oito repetições e três animais por unidade experimental. Os tratamentos corresponderam às seguintes relações treonina e lisina digestíveis: 0,$50 ; 0,57 ; 0,64 ; 0,71$; 0,78 . Foram avaliados o desempenho dos leitões e os valores de haptoglobina e escore fecal por períodos: Período I - dos 28 aos 42 dias e Período II - dos 28 aos 49 dias. As relações de treonina e lisina digestíveis não influenciaram o consumo de ração médio diário e o ganho de peso médio diário dos animais. Houve efeito quadrático dos tratamentos em relação à conversão alimentar nos períodos I e II. Não houve efeito dos tratamentos sobre os teores haptoglobina e escore fecal no quinto e décimo dia do período experimental. As melhores relações treonina digestível com lisina digestível encontradas para conversão alimentar foram as de 0,629 e 0,648 , respectivamente para os períodos I ( 28 aos 42 dias de idade) e II ( 28 aos 49 dias de idade).

Palavras-chave: aminoácido industrial, desempenho, proteína ideal

\section{SUMMARY}

This study was conducted in order to determine the best relations of threonine with lysine for pigs from 28 to 49 days of age. For this 120 commercial crossbred pigs with high genetic potential for lean meat in the carcase, weaned at 28 days of age with an average initial weight of $7.45 \mathrm{~kg}$ were used. The animals were allotted to a randomized block design, with five treatments (ratios of threonine and lysine) and controlling the initial weight, with eight replications and three animals per experimental unit. The treatments were the following digestible threonine and lysine: $0.50 ; 0.57 ; 0.64 ; 0.71$; 0.78. - From 28 to 42 days and Period II - 28 to 49 days of Period I: piglet performance and values of haptoglobin and faecal score by periods were evaluated. The relations of threonine and lysine did not affect average daily feed intake and average daily weight gain of the animals. Quadratic effect of treatments on the feed conversion in periods I and II. There was no effect of treatments on haptoglobin levels and fecal score in the fifth and tenth day of the trial period. Best digestible threonine to lysine found for feed conversion were 0,629 and 0 648 , respectively for the I ( 28 to 42 days old) and II ( 28 to 49 days of age) periods.

Keywords: industrial amino acid, performance, ideal protein 
Rev. Bras. Saúde Prod. Anim., Salvador, v.15, n.3, p.679-688 jul./set., 2014 http://www.rbspa.ufba.br ISSN 15199940

\section{INTRODUÇÃO}

A produtividade de um rebanho de suínos pode ser aferida pelo número de animais desmamados/porca/ano já que isso é resultado direto de um correto manejo alimentar e sanitário e de cuidados adequados com a leitegada recém-nascida. Além desses fatores, a idade de desmama dos leitões tem sido o parâmetro de maior significado nesse índice, o que ocasionou a redução nos dias de lactação como forma de aumentar o número de leitões desmamados/porca/ano.

Assim, a idade à desmama que há algumas décadas já foi de quase 50 dias passou a acontecer aos $18-21$ dias de vida desse animal. Contudo, o desmame precoce realizado em idade inferior aos 24 dias, pode ser crítico para os leitões em razão de vários fatores estressantes como troca de uma dieta líquida constituída à base de proteína animal para outra sólida à base de proteína vegetal, separação da mãe, mudança de ambiente, alterações na temperatura ambiental, dificuldade de adaptação a comedouros e bebedouros além da mistura de leitegadas.

Vale salientar que os animais desmamados aos 24 ou mais dias de vida também encontram dificuldades, principalmente no que diz respeito à adaptação a um novo ambiente e a uma nova dieta, entretanto, leitões desmamados com 26 dias de idade ou mais estão mais maduros fisiologicamente, o que acarreta em menor estresse e maior consumo da dieta (GRANÃ et al., 2010).

A treonina tem importante papel na manutenção da saúde dos suínos, em especial dos leitões mais jovens, pois é responsável pela produção de muco intestinal aumentando a imunidade dos leitões frente às bactérias patogênicas. Essa produção do muco intestinal é relevante para manutenção da integridade de defesas inespecíficas da parede intestinal, papal fundamental da treonina que é responsável pela síntese de mucinas (LAW et al. 2007; WANG et al., 2007).

$\mathrm{Na}$ tentativa de ultrapassar esse período de desafio, dietas elaboradas com melhor qualidade dos ingredientes vêm sendo mais utilizadas, no entanto, têm sido constatadas variações na literatura quanto às relações da treonina com lisina, tanto digestíveis quanto totais recomendadas. E segundo Rostagno et al. (2011), devem ser de 100:63 (lisina: treonina).

Objetivou-se determinar as melhores relações treonina e lisina digestíveis em dietas para leitões desmamados aos 28 dias de idade nos períodos I (28 aos 42 dias de idade) e II (28 a 49 dias de idade).

\section{MATERIAIS E MÉTODOS}

O experimento foi conduzido no Setor de Suinocultura do Departamento de Zootecnia da Universidade Federal de Viçosa, localizada no município de Viçosa-MG, no período compreendido entre fevereiro e abril de 2012.

O experimento foi realizado após avaliação do Comitê de Ética do Departamento de Zootecnia da mesma universidade (processo $n^{\circ} 76 / 2010$ ) e os cuidados e uso dos leitões foram realizados de acordo com as normas para uso de animais em experimentos.

Foram utilizados 120 leitões híbridos, de alto potencial genético, desmamados aos 28 dias de idade. Os leitões com peso inicial de $7,45 \pm 0,92 \mathrm{~kg}$ foram distribuídos no experimento em blocos casualizados, com cinco tratamentos e oito repetições de três animais por unidade experimental. A unidade experimental foi constituída pela gaiola 
e na formação de blocos foi considerado como critério o peso inicial dos animais. Os tratamentos consistiram em cinco relações treonina digestível com lisina digestível $(0,50 ; 0,57 ; 0,64 ; 0,71 ; 0,78)$, essas relações foram estabelecidas a partir dos níveis de treonina digestível: 0,$665 ; 0,759 ; 0,853 ; 0,946$ e 1,041 e fixado o o nível de $1,33 \%$ para lisina.

As instalações foram limpas, desinfetadas e antibiótico (Colistina) foi adicionado como promotor de crescimento nas dietas experimentais.

Os animais foram alojados dos 28 aos 49 dias em creches metálicas suspensas com piso e laterais telados providas de comedouros semiautomáticos e bebedouros tipo chupeta localizados em galpão de alvenaria, com piso de concreto, teto de madeira rebaixado e janelas basculantes nas laterais.

As dietas experimentais (Tabela 1) foram formuladas para atender às necessidades dos leitões na fase inicial de crescimento seguindo-se as recomendações contidas em Rostagno et al. (2011), exceto com relação aos aminoácidos estudados. O inerte (areia lavada) foi usado em todas as dietas para assegurar a variação na inclusão de aminoácidos.

Os animais tiveram livre acesso à água e às rações experimentais.

As temperaturas de máxima e de mínima no interior das creches foram registradas diariamente às sete horas da manhã usando termômetro de máxima e mínima colocados na parte mediana do galpão a uma altura de $1,5 \mathrm{~m}$.

As rações, as sobras e os desperdícios foram pesados periodicamente e os animais pesados individualmente no início e no final de cada período experimental para determinação do consumo de ração, do ganho de peso e da conversão alimentar.

Foram avaliados os parâmetros de desempenho dos leitões (ganho de peso, consumo de ração, conversão alimentar) e o teor de haptoglobina por períodos: Período I - dos 28 dias aos 42 dias de idade e Período II - dos 28 aos 49 dias de idade.

Rostagno et al. (2005) consideraram como fase única o período em que os animais se encontram com peso entre $7 \mathrm{e}$ $15 \mathrm{~kg}$. No presente estudo, em que a faixa de peso observada ficou entre 7 e $14 \mathrm{~kg}$, essa fase foi ainda subdividida em duas. Sendo o estresse pós-desmame mais acentuado nas 2 primeiras semanas, como o primeiro período foi fixado entre o $28^{\circ}$ ao $42^{\circ}$ dia, de maneira a dimensionar o efeito desse estresse sobre os animais, pelo mesmo motivo nesse período foram coletadas as amostras de sangue para avaliação dos teores de haptoglobina e escore fecal.

Já o segundo período foi fixado do $28^{\circ}$ ao $49^{\circ}$ dia de idade, com essa segunda subdivisão pretendeu-se fazer uma análise da média dos parâmetros avaliados do período como um todo, ou seja, compreendendo tanto o período de pico de estresse como aquele em que os animais já haviam superado esse momento (após as 2 primeiras semanas pós-desmame).

No quinto e décimo dia após o início experimental, foi avaliado o escore fecal dos leitões, esse escore foi realizado de forma visual, em que foram dadas notas de 1 a 5 para as fezes de cada unidade experimental. $\mathrm{O}$ escore 1 correspondeu às fezes de consistência normal, $\mathrm{o}$ escore 2, às fezes pastosas, o escore 3, às fezes aquosas e o escore 4, fezes sanguinolentas.

No $14^{\circ}$ dia após o início do experimento foram coletadas amostras de sangue, por meio de punção no sinus orbital de dois animais por unidade experimental (o mais pesado e o mais leve) para análises de haptoglobina no plasma sanguíneo. 
Rev. Bras. Saúde Prod. Anim., Salvador, v.15, n.3, p.679-688 jul./set., 2014 http://www.rbspa.ufba.br ISSN 15199940

Tabela 1. Composição centesimal, química e energética das dietas experimentais

\begin{tabular}{|c|c|c|c|c|c|}
\hline \multirow{2}{*}{ Ingredientes (composição centesimal) } & \multicolumn{5}{|c|}{ Relações Treonina/Lisina digestíveis } \\
\hline & 0.50 & 0.57 & 0.64 & 0.71 & 0.78 \\
\hline Milho & 55,105 & 55,105 & 55,105 & 55,105 & 55,105 \\
\hline Farelo de soja & 19,270 & 19,270 & 19,270 & 19,270 & 19,270 \\
\hline Soja micronizada & 5,000 & 5,000 & 5,000 & 5,000 & 5,000 \\
\hline Leite em pó desnatado & 11,000 & 11,000 & 11,000 & 11,000 & 11,000 \\
\hline Lactose & 4,300 & 4,300 & 4,300 & 4,300 & 4,300 \\
\hline Açúcar & 1,331 & 1,331 & 1,331 & 1,331 & 1,331 \\
\hline Fosfato Bicálcico & 1,422 & 1,422 & 1,422 & 1,422 & 1,422 \\
\hline Calcário & 0,814 & 0,814 & 0,814 & 0,814 & 0,814 \\
\hline Sal comum & 0,438 & 0,438 & 0,438 & 0,438 & 0,438 \\
\hline L-Lisina $\mathrm{HCl}$ & 0,444 & 0,444 & 0,444 & 0,444 & 0,444 \\
\hline DL-Metionina & 0,185 & 0,185 & 0,185 & 0,185 & 0,185 \\
\hline L-triptofano & 0,030 & 0,030 & 0,030 & 0,030 & 0,030 \\
\hline L-treonina & 0,000 & 0,095 & 0,191 & 0,286 & 0,383 \\
\hline L-Valina & 0,048 & 0,048 & 0,048 & 0,048 & 0,048 \\
\hline Suplemento Mineral $^{1}$ & 0,100 & 0,100 & 0,100 & 0,100 & 0,100 \\
\hline Suplemento Vitamínico ${ }^{2}$ & 0,100 & 0,100 & 0,100 & 0,100 & 0,100 \\
\hline Promotor de crescimento ${ }^{3}$ & 0,010 & 0,010 & 0,010 & 0,010 & 0,010 \\
\hline Antioxidante & 0,020 & 0,020 & 0,020 & 0,020 & 0,020 \\
\hline Inerte $^{4}$ & 0,383 & 0,288 & 0,192 & 0,097 & 0,000 \\
\hline Total & 100,000 & 100,000 & 100,000 & 100,000 & 100,000 \\
\hline \multicolumn{6}{|c|}{ Composição energética e química calculada } \\
\hline EM (Mcal/kg) & 3,345 & 3,349 & 3,353 & 3,356 & 3,360 \\
\hline Proteína bruta & 19,280 & 19,354 & 19,429 & 19,503 & 19,579 \\
\hline Lisina dig. & 1,331 & 1,331 & 1,331 & 1,331 & 1,331 \\
\hline Met.+Cist. dig. & 0,746 & 0,746 & 0,746 & 0,746 & 0,746 \\
\hline Triptofano dig. & 0,240 & 0,240 & 0,240 & 0,240 & 0,240 \\
\hline Treonina dig. & 0,665 & 0,759 & 0,853 & 0,946 & 1,041 \\
\hline Rel. Treo/Lis & 0,500 & 0,570 & 0,630 & 0,710 & 0,780 \\
\hline Valina digestível & 0,919 & 0,919 & 0,919 & 0,919 & 0,919 \\
\hline $\mathrm{P}$ disponível & 0,451 & 0,451 & 0,451 & 0,451 & 0,451 \\
\hline Cálcio & 0,861 & 0,861 & 0,861 & 0,861 & 0,861 \\
\hline Sódio & 0,230 & 0,230 & 0,230 & 0,230 & 0,230 \\
\hline Lactose & 8,039 & 8,039 & 8,039 & 8,039 & 8,039 \\
\hline \multicolumn{6}{|c|}{$\begin{array}{l}{ }^{1} \text { Conteúdo por quilo de ração: } 100 \mathrm{mg} \text { ferro, } 10 \mathrm{mg} \text { cobre, } 40 \mathrm{mg} \text { manganês, } 1000 \mathrm{mg} \text { zinco, } 1 \mathrm{mg} \\
\text { cobalto, } 1,5 \mathrm{mg} \text { iodo. } \\
{ }^{2} \text { Conteúdo por quilo de ração: vitamina } \mathrm{A}\left(10.000 \text {. UI), vitamina } \mathrm{D}_{3}(2.000 \mathrm{UI}) \text {, vitamina } \mathrm{E}(40 . \mathrm{UI}) \text {, }\right. \\
\text { vitamina } \mathrm{K}_{3}(2 \mathrm{mg}) \text {, vitamina } \mathrm{B}_{12}(20 \mathrm{mg}) \text {, vitamina } \mathrm{B}_{2}(6 \mathrm{mg}) \text {, biotina }(22,5 \mathrm{mg}) \text {, niacina }(30 \mathrm{mg}) \text {, ácido } \\
\text { pantotênico }(16 \mathrm{mg}) \text {, antioxidante }(0,1 \mathrm{mg}), \mathrm{B}_{1}(1,5 \mathrm{mg}) \text {, vitamina } \mathrm{B}_{6}(2 \mathrm{mg}) \text {, ácido fólico }(0,6 \mathrm{mg}) \text {. } \\
{ }^{3} \text { Princípio ativo: Colistina. } \\
{ }^{4} \text { Inerte: Areia lavada. }\end{array}$} \\
\hline
\end{tabular}

Após um período de jejum de 13 horas, os leitões receberam novamente dieta à vontade por um período de duas horas. Decorrido este tempo, um novo jejum foi realizado até às 13 horas, quando se realizou a coleta de sangue. O sangue coletado foi transferido para tubos contendo 14,3UI de heparina sódica. Em seguida, o sangue foi centrifugado durante 20 minutos para obtenção do plasma $( \pm 1,5 \mathrm{~mL})$, que então foi transferido para frascos apropriados. Os 
Rev. Bras. Saúde Prod. Anim., Salvador, v.15, n.3, p.679-688 jul./set., 2014 http://www.rbspa.ufba.br ISSN 15199940

frascos foram armazenados em congelador $\left(-18^{\circ} \mathrm{C}\right)$.

A concentração plasmática da haptoglobina, proteína de fase aguda em suínos, foi determinada por ensaio de colorimetria (fase de teste haptoglobina T801), utilizando os kits Haptoglobin (TP801, Tri-Delta Development LTDA, Kildare, Irlanda), sendo que a sensibilidade foi determinada como 0,05 $\mathrm{mg} / \mathrm{ml}$ de haptoglobina de acordo com Le Floc'h et al. (2009).

As variáveis de desempenho foram analisadas utilizando-se os procedimentos para análise de variância e de regressão por polinômios ortogonais do SAS versão 9.2 (STATISTICAL ANALYSIS SYSTEM, 2000). A determinação da relação treonina digestível com a lisina digestível foi obtida com base nos resultados de consumo de ração diário, ganho de peso diário, conversão alimentar, haptoglobina e escore fecal usando os modelos de regressão linear e/ou quadrática. Foi utilizado o coeficiente de determinação ajustado $\left(\mathrm{R}^{2}\right)$ para determinar o melhor modelo para cada variável estudada. Valores de probabilidade menores que $5,0 \%$ foram considerados significativos.

\section{RESULTADOS E DISCUSSÃO}

Os valores médios das temperaturas máximas observados durante o período experimental foram de $28,9 \pm 1,0^{\circ} \mathrm{C}$ e das temperaturas mínimas foram de 25,4 \pm $1,2^{\circ} \mathrm{C}$. Com base nestes valores, pode-se inferir que as temperaturas médias de máxima e mínima ficaram acima da zona de conforto térmico, indicado por Campos et al. (2009) que consideraram como temperatura ideal para suínos na fase de creche situada entre 20 e $24{ }^{\circ} \mathrm{C}$ na primeiras semanas de alojamento na creche, e em torno de $20^{\circ} \mathrm{C}$ nas últimas semanas. Nesse sentido, os animais foram submetidos ao estresse térmico.

Os resultados de desempenho, teor de haptoglobina e escore fecal estão descritos na Tabela 2.

Tabela 2. Desempenho, teor de haptoglobina no plasma dos leitões e escore fecal em função das relações de treonina: lisina digestíveis das rações experimentais nos períodos de 28 aos 42 dias de idade e dos 28 aos 49 dias de idade

\begin{tabular}{|c|c|c|c|c|c|c|c|}
\hline \multirow{2}{*}{ Variáveis } & \multicolumn{5}{|c|}{ Relações de treonina: lisina digestíveis } & \multirow{2}{*}{$\mathrm{CV}(\%)^{1}$} & \multirow{2}{*}{ P-valor } \\
\hline & 0,50 & 0,57 & 0,64 & 0,71 & 0,78 & & \\
\hline \multicolumn{8}{|c|}{28 aos 42 dias idade (Período I) } \\
\hline Pesos iniciais $(\mathrm{kg})$ & 7,43 & 7,48 & 7,44 & 7,46 & 7,45 & 0,86 & 0,664 \\
\hline Pesos finais $(\mathrm{kg})$ & 10,25 & 10,79 & 10,46 & 10,23 & 10,24 & 6,08 & 0,340 \\
\hline Consumo de ração (g/dia) & 302 & 331 & 294 & 280 & 312 & 18,21 & 0,446 \\
\hline Ganho de peso (g/dia) & 201 & 237 & 216 & 198 & 199 & 21,27 & 0,377 \\
\hline Conversão alimentar ${ }^{2}$ & 1,52 & 1,42 & 1,37 & 1,43 & 1,58 & 10,25 & 0,005 \\
\hline Haptoglobina (mg/dl) & 21,79 & 20,68 & 25,29 & 18,56 & 19,86 & 52,66 & 0,513 \\
\hline Notas escore Fecal- $5^{\circ}$ dia & 1,87 & 1,50 & 1,75 & 1,62 & 1,75 & 46,30 & 0,899 \\
\hline Notas escore Fecal- $10^{\circ}$ dia & 1,00 & 1,13 & 1,13 & 1,13 & 1,00 & 26,37 & 0,760 \\
\hline \multicolumn{8}{|c|}{28 aos 49 dias idade (Período II) } \\
\hline Pesos iniciais $(\mathrm{kg})$ & 7,43 & 7,48 & 7,44 & 7,46 & 7,45 & 0,86 & 0,664 \\
\hline Pesos finais (kg) & 13,65 & 14,35 & 14,27 & 13,58 & 13,56 & 6,61 & 0,241 \\
\hline Consumo de ração (g/dia) & 389 & 406 & 365 & 333 & 380 & 14,54 & 0,115 \\
\hline Ganho de peso (g/dia) & 296 & 327 & 325 & 292 & 291 & 14,18 & 0,248 \\
\hline Conversão alimentar ${ }^{2}$ & 1,31 & 1,25 & 1,12 & 1,15 & 1,31 & 8,99 & 0,002 \\
\hline
\end{tabular}


Não foi observado efeito $(\mathrm{P}<0,05))$ das relações treonina e lisina sobre $\mathrm{O}$ consumo de ração dos animais nos períodos I e II. Os achados no presente trabalho é semelhante aos resultados encontrados por Zhang et al. (2014) ao avaliarem níveis crescentes de treonina para leitões em crescimento (6 a $32 \mathrm{~kg}$ ), e também por Wang et al. $(2006,2007)$ que não constataram variação significativa no consumo médio de ração dos leitões, quando avaliaram níveis de treonina e lisina digestíveis da ração para suínos jovens.

Tais trabalhos demonstram que os leitões são capazes de tolerar consideráveis excessos de aminoácidos sem que ocorra diferença significativa no consumo voluntário de ração por esses animais.

Os resultados diferem dos obtidos por Pozza et al. (2000), os quais, em experimento com níveis de suplementação de treonina para leitoas (15-30kg), observaram efeito quadrático para o consumo de ração. Ainda segundo trabalhos conduzidos por Torrallardona \& Solà-Oriol (2009) em dietas com 4\% de excesso de aminoácidos essenciais, houve uma preferência por dietas com excesso de lisina, treonina e arginina pelos suínos em comparação com aquelas com excesso de metionina e triptofano.

Por outro lado, quando aos suínos foi dada opção de escolha de aminoácidos em tais relatos, não foi possível verificar uma seleção consistente pelo aminoácido lisina, ao passo que, mais recentemente, outros experimentos com leitões desmamados sugeriram que os animais optavam por dietas com maior teor de lisina.

Pode-se inferir a partir desses relatos que os suínos são eficientes em selecionar aminoácidos para apoiar suas necessidades, mas raramente são capazes de equilibrar suas dietas para combinar com sua demanda de forma exata. Quando o consumo de um aminoácido específico (alimentação de escolha) foi investigado para suínos em crescimento, dietas equilibradas têm sido preferidas àquelas desequilibradas.

As diferenças entre os resultados dos experimentos podem estar relacionadas às diferentes faixas de peso e estádio de desenvolvimento dos animais analisados nos experimentos, além de outros fatores metabólicos e fisiológicos.

Em relação ao ganho de peso dos leitões não foi verificada diferença $(\mathrm{P}>0,05)$ entre os tratamentos em ambos os períodos. Zhang et al. (2014), ao avaliarem níveis crescentes de treonina para leitões desmamados aos 21 dias, também não observaram influência dos níveis deste aminoácido sobre o ganho de peso, o que indica que a redução dos seus níveis foi tal que não comprometeu a deposição de proteína desses animais.

Resultados similares também foram encontrados por Pozza et al. (2000) e Paiano et al. (2009) que trabalharam com diferentes níveis de treonina para leitões em fase de crescimento. Ainda segundo Hamard et al. (2007). em estudos desenvolvidos com leitões jovens desmamados precocemente e avaliando níveis de treonina digestível com lisina digestível por um período de duas semanas, verificou-se que tal intervalo de tempo pode ser insuficiente para induzir a diferenças na taxa de crescimento. O que pode ser estendido ao presente estudo, em que se analisou os animais por um período de três semanas.

Por outro lado, Wang et al. (2007) constataram que a ingestão deficiente de treonina reduz a síntese das proteínas no músculo esquelético e hepático dos leitões pós-desmamados, quando foi administrado reduções drásticas de treonina (relação de $33 \%$ tre:lis) fato não observado no presente trabalho. Há poucas informações a respeito de seus efeitos sobre a síntese proteica nos tecidos extra-intestinais. 
Rev. Bras. Saúde Prod. Anim., Salvador, v.15, n.3, p.679-688 jul./set., 2014 http://www.rbspa.ufba.br ISSN 15199940

Houve efeito quadrático $(\mathrm{P}<0,05)$ das relações treonina: lisina digestível sobre a conversão alimentar dos animais nos períodos I e II, segundo as equações: $\hat{Y}=$ $8,8921 X^{2}-11,1962 X+4,9002\left(r^{2}=0,99\right)$ e $\hat{Y}=8,7464 X^{2}-11,3382 X+4,8162$ $\left(r^{2}=0,84\right)$, indicando que as melhores estimativas de 1,37 e 1,14 foram obtidas com rações contendo relações de 0,629 e
0,648 treonina: lisina, respectivamente (Figuras 1 e 2). Pode-se inferir que o efeito observado das relações de treonina sobre as conversões alimentares (índice produtivo) ocorreu devido ao menor coeficiente de variação observado nessa variável, fato que não foi presenciado pelo ganho de peso diário e consumo de ração diário.

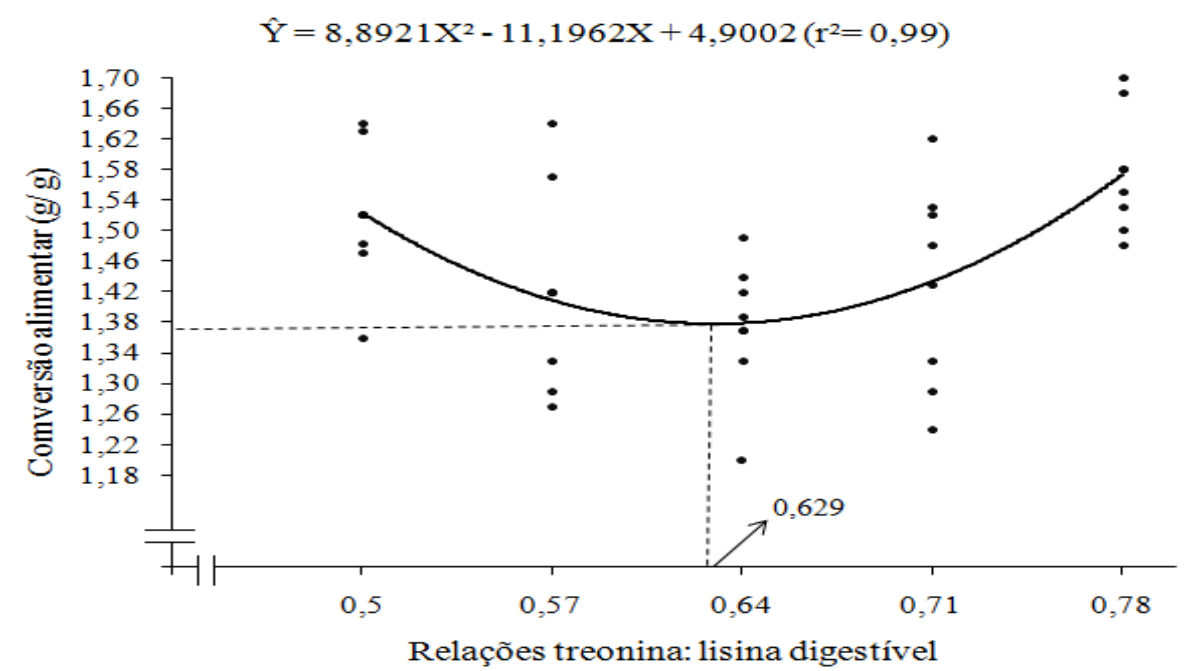

Figura 1. Efeito das relações treonina digestível com lisina digestível sobre a conversão alimentar dos leitões no período I ( 28 aos 42 dias de idade)

$$
\hat{\mathrm{Y}}=8,7464 \mathrm{X}^{2}-11,3382 \mathrm{X}+4,8162\left(\mathrm{r}^{2}=0,84\right)
$$

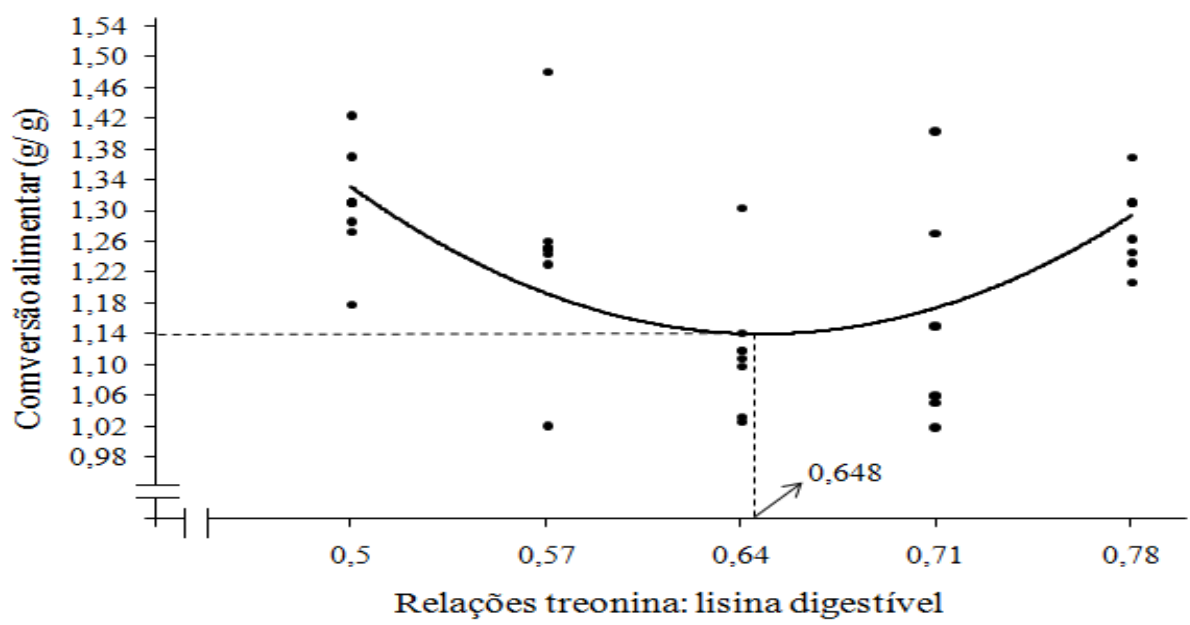

Figura 2. Efeito das relações treonina digestível com lisina digestível sobre a conversão alimentar dos leitões no período II ( 28 aos 49 dias de idade) 
Os melhores valores observados são semelhantes aos verificados por Lenehan et al. (2003), que encontraram o valor de $64,0 \%$ como a relação ótima de treonina: lisina digestíveis nas dietas para suínos de 10 a $20 \mathrm{~kg}$, e também aos encontrados por James et al. (2002) que estimaram a relação ótima em $65,0 \%$ para animais de 10 a $20 \mathrm{~kg}$ e de 7 a $14 \mathrm{~kg}$, respectivamente. Além disso, Li et al. (1999) constatou que o requerimento dos animais por treonina: lisina digestíveis é de aproximadamente $60,0 \%$ para crescimento e desenvolvimento de tecidos e de $67,0 \%$ em casos de o sistema imune estar ativado.

As divergências nas estimativas das necessidades de treonina de leitões encontradas na literatura que proporcionaram melhores respostas de desempenho podem estar relacionadas além da diferença do nível de proteína das rações experimentais, às diferenças de genótipos, teores de energia e da composição em matérias-primas das rações experimentais, à diferença da digestibilidade da treonina nos alimentos utilizados na formulação das dietas, aos critérios utilizados pelos pesquisadores para avaliação das exigências, à temperatura ambiente, ao grau de ativação do sistema imunológico dos animais e também aos níveis dos demais aminoácidos limitantes das rações.

Não houve efeitos significativos $(\mathrm{P}>0,05)$ dos tratamentos sobre os teores haptoglobina e escore fecal aos cinco e dez dias após o início do experimento. Os valores de escores fecais aos 49 dias, tanto aos cinco, como aos dez dias de experimento apresentaram-se baixos e não foram afetados pelas relações treonina e lisinas digestíveis. Provavelmente, o fato de os leitões terem sido criados em instalações limpas, desinfetadas e possuírem antibiótico nas rações, pode ter sido responsável pela menor incidência de diarreias e pelos valores de escore fecal e haptoglobina terem se mantido baixos e não terem sido alterados pelos diferentes níveis de treonina.

Estes dados corroboram os relatos de Zangeronimo et al. (2006), Niewold et al. (2007), Hamard et al. (2007) e Le Floc'h et al. (2009) que trabalharam com leitões jovens criados em ambientes sem desafio sanitário, com a presença de antibiótico nas rações e não observaram doenças clínicas e diarreia durante tal análise, além de não terem sido observadas diferenças nos teores de haptoglobina nos grupos experimentais analisados.

As melhores relações treonina digestível com lisina digestível para a conversão alimentar foram as de 0, 629 e 0, 648, respectivamente para os períodos I (28 aos 42 dias de idade) e II ( 28 aos 49 dias de idade).

\section{AGRADECIMENTOS}

Os autores agradecem à Fundação de Amparo à Pesquisa do Estado de Minas Gerais (Fapemig) pelo financiamento do projeto de pesquisa no qual este experimente está inserido, ao Conselho Nacional de Desenvolvimento Científico e Tecnológico (CNPq) pela bolsa de Iniciação Científica e aos funcionários do Setor de Suinocultura da Universidade Federal de Viçosa $(U F V)$.

\section{REFERÊNCIAS}

BISINOTO, K.S.; BERTO, D.A.; CALDARA, F.R.; TRINDADE NETO, M.A.D.; WECHSLER, F.S. Threonine: lysine ratios for piglets from 6 to $11 \mathrm{~kg}$ of live weight in diets based on the ideal protein concept. Ciência Rural, v.37, n.6, p.1740-1745, 2007. 
Rev. Bras. Saúde Prod. Anim., Salvador, v.15, n.3, p.679-688 jul./set., 2014 http://www.rbspa.ufba.br ISSN 15199940

CAMPOS, J.A.; TINÔCO, I.D.F.; BAÊTA, F.D.C. Qualidade do ar, ambiente térmico e desempenho de suínos criados em creches com dimensões diferentes. Engenharia Agrícola, v.29, n.3, p.339-347, 2009.

GRAÑA, G.L.; FERREIRA, A.S.; de OLIVEIRA SILVA, F.C., GRAÑA, A.L.; GARCIA DE ARAÚJO, W.A.; Carlos, C.M. Plasma sanguíneo em dietas sem antibióticos para leitões desmamados aos 21 dias de idade.

Revista Brasileira de Saúde e Produção Animal [online], v.11, n.3, 2010.

HAMARD, B.; SE 'VE, B.; LE FLOC'H, N. Intestinal development and growth performance of early-weaned piglets fed a low-threonine diet.INRA, UMR1079. Syste'mes d'Elevages Nutrition Animale et Humaine, F35590, 2007.

JAMES, B.W.; TOKACH, M.D.; GOODBAND, R.D. The optimal true ileal digestible lysine requirement for nursery pigs between 27 to $44 \mathrm{lb}$. Swine Day, p.63-65, 2002.

LAW, G.K.; BERTOLO, R.F.; ADJIRIAWERE, A.; PENCHARZ, P.B.;

BALL, R.O. Adequate oral threonine is critical for mucin production and gut function in neonatal piglets. American Journal of PhysiologyGastrointestinal and Liver Physiology, v.292, n.5, p.1293-1301, 2007.

LE FLOC'H, N.; LE BELLEGO, L.; MATTE, J.J.; MELCHIOR, D.; SÈVE, B. The effect of sanitary status degradation and dietary tryptophan content on growth rate and tryptophan metabolism in weaning pigs. Journal of Animal Science, v.87, p.1686-1694, 2009.
LENEHAN, N.A.; DRITZ, S.S.; TOKACH, M.D.; GOODBAND, R.D.; NELSSEN, J.L.; USRY, J.L. Effects of Lys level fed from 10 to $20 \mathrm{~kg}$ on growth performance of barrows and gilts. Journal of Animal Science, v.81, p.183, 2003.

LI, D.F.; XIAO, C.T.; QIAO, S.Y.; ZHANG, J.H.; JOHNSON, E.W.; THACKER, P. A. Effects of dietary threonine on performance, plasma parameters and immune function of growing pigs. Animal Feed Science Technological, v.78, p.179-188, 1999.

NIEWOLD, T.A. The nonantibiotic anti-inflammatory effect of antimicrobial growth promoters, the real mode of action? A hypothesis. Poultry Science, v.86, p.605-609, 2007.

PAIANO, D.; MOREIRA, I.; SILVESTRIN, N.; CARVALHO, P.L.; PERDIGÃO, L.S. Relações treonina: lisina digestíveis para suínos na fase inicial, alimentados com rações de baixa proteína, calculadas de acordo com o conceito de energia líquida. Arquivo Brasileiro de Medicina Veterinária e Zootecnia, v.61, n.1, p.211-218, 2009.

POZZA, P.C.; GOMES, P.C.;

DONZELE, J.L. Exigência de treonina para leitoas dos 15 aos $30 \mathrm{~kg}$. Revista Brasileira de Zootecnia, v.29, n.3, p.817-822, 2000.

ROSTAGNO, H.S.; ALBINO, L.F.T.; DONZELE, J.L. Tabelas brasileiras para aves e suínos: composição de alimentos e exigências nutricionais. Viçosa, MG: Universidade Federal de Viçosa, 2005. 186p. 
Rev. Bras. Saúde Prod. Anim., Salvador, v.15, n.3, p.679-688 jul./set., 2014 http://www.rbspa.ufba.br ISSN 15199940

ROSTAGNO, H.S., ALBINO, L.F.T., DONZELE, J.L. Tabelas Brasileiras para Aves e Suínos: composição de alimentos e exigências nutricionais. 3.ed. Viçosa, MG: Universidade Federal de Viçosa, 2011. 252p.

\section{SAS INSTITUTE. Statistical analysis system institute Inc. SAS/STAT} User's Guide. V. 8.0. Cary, NC, 2000. v.1.

TORRALLARDONA, D.; SOLÀORIOL, D. Evaluation of free-choice feedstuffs preference by pigs. Voluntary Feed Intake in Pigs. Wageningen: Wageningen Academic Publishers, 2009. p.215-242.

WANG, X.; QIAO, S.Y.; LIU, M.; MA, Y.X. Effects of graded levels of true ileal digestible threonine on performance, serum parameters and immune function of $10-25 \mathrm{~kg}$ pigs. Animal feed science and technology, v.129, n.3, p.264-278, 2006.

WANG, X.; QIAO, S.; YIN, Y.; YUE, L.; WANG, Z.; WU, G. A deficiency or excess of dietary threonine reduces protein synthesis in jejunum and skeletal muscle of young pigs. The Journal of nutrition, v.137, n.6, p.1442-1446, 2007.
WASSELL, J. Haptoglobin: function and polymorphism. Clinical

Laboratory, v.46, p.547-552, 2000.

ZANGERONIMO, M.G.; FIALHO, E.T.; LIMA, J.D.F.; RODRIGUES, P.B.; MURGAS, L.D.S. Redução do nível de proteína bruta da ração suplementada com aminoácidos sintéticos para leitões na fase inicial.

Revista Brasileira de Zootecnia, v.35, n.3, p.849-856, 2006.

ZHANG, Z.F.; KIM, I.H. Effects of dietary threonine: lysine ratios on growth performance, blood urea nitrogen, and nitrogen balance in weaned pigs. Journal of Applied Animal Research, v.42, n.4, p.1-5, 2014.

Data de recebimento: 08/01/2014

Data de aprovação: 15/07/2014 